\title{
Human Capital and Export Decisions: The Case of Small and Medium Enterprises in Kosovo
}

\section{Petrit Gashi}

Faculty of Economics, University of Prishtina, Kosovo petrit.gashi@uni-pr.edu
CroEconSur

Vol. 16

No. 2

December 2014

pp. $91-120$

Received: September 11, 2014 Accepted: November 13, 2014

Research Article

doi:10.15179/ces.16.2.4

\section{Abstract}

Following the propositions of firm internationalization theories including the Melit'z dynamic model of export participation, this paper investigates the effects of human capital on the export decisions of Kosovo's firms. Using a unique dataset of around 500 Small and Medium Enterprises, econometric estimates show mixed indications regarding the relationship between the propensity to export and longevity in export markets and human capital variables, measured by the education of the workforce, and investment in training. While education generally has a negative effect on exporting decisions, the latter shows a consistent positive effect. In the context of Kosovo, this dichotomy may reflect in part the effect of the underperforming education system in Kosovo, which does not produce the right level and/or mix of skills required by the private sector; this, in turn, forces SMEs to invest in increasing workforce capacities. Another 
explanation may indicate the lack of demand for a better skilled workforce, either because of associated high costs, or because a significant number of firms in Kosovo operate in low-value activities that do not require advanced skills and knowledge. Other factors that affect the decisions of firms to enter and serve export markets are found to be firm size, experience, growth, and adoption of quality standards.

Keywords: Kosovo, export decisions, human capital, productivity

JEL classification: F14, F23, P33

\section{Introduction 1}

With the conclusion of the Stabilisation and Association Agreement (SAA) expected in 2015, Kosovo will enter into a new phase of trade relations with the EU. The SAA will upgrade Kosovo-EU trade relations from the Autonomous Trade Measures (ATM) to a full-fledging Free Trade Agreement (FTA), liberalizing almost fully trade exchanges in both directions. The signing of the SAA with the EU and the ensuing FTA means that Kosovo will liberalize its trade with its major trade partners. In addition to the CEFTA agreement and the FTA with Turkey, the FTA with the EU will liberalize 80 percent of Kosovo trade in goods with the world. The liberalization of trade has been the main ingredient of the trade policy in post-war Kosovo, aiming at reducing the large and persisting trade deficit in goods. ${ }^{2}$ The Government has resisted the pressure to impose tariff and non-tariff barriers to shield domestic industries. Furthermore, trade-related sectoral policies remained largely within the confines of policies aiming at improving general business conditions in the country.

1 I would like to thank Artane Rizvanolli, two anonymous referees, and the editors for very helpful comments and suggestions.

2 For more on the developments in the external sector in Kosovo see Gashi and Pugh (2014). 
The course of trade liberalization has been seen as a way to access major regional and global markets, and a potential route to attract capital, technology, and knowledge. However, the liberalization approach did not deliver the expected outcomes; Kosovo producers still find it difficult to access foreign markets, primarily as a result of non-tariff barriers. On the other hand, the inflow of foreign capital is negligible due to an unfavorable business climate. Hence, in the context of the new developments regarding the Kosovo-EU trade relations, some issues are re-emerging. What will be the impact of the FTA with the EU on the already deep trade deficit in goods? What will be the FTA impact on employment and welfare? What will the fiscal impact be, and how will the revenue gap be closed? There are fears that, at least in the short- to mediumterm, the FTA with the EU will further deepen the trade deficit in goods and even deteriorate the surprisingly positive trade balance in services. In addition, the fiscal impact will be a significant burden, and alternatives to closing the gap without producing additional disturbances are rather narrow in the current economic setting. Furthermore, there are growing fears that with the FTA domestic producers will lose ground, even in the local market, as a result of low levels of competitiveness. In the latter case, there are concerns that the FTA with the EU will further prolong the deindustrialization of Kosovo's economy that began in the early nineties.

Another puzzling question remains if Kosovo, taking into account economy-wide structural problems and especially the low levels of country's supply capacity, will be able to fully utilize the conventional gains from the trade liberalization with the EU. This question has been raised frequently in the literature and has been tested empirically (Bhagwati, 2002; Redding and Venables, 2003; Hoekman and Javorcik, 2004; Correa, Dayoub, and Francisco, 2007; Gashi and Pugh, 2014). For instance, Baghwati (2002) argues that trade liberalization may not lead to the expected gains when market imperfections (e.g., labor market rigidities, sunk-costs, and incomplete financial markets) prevent resources from being efficiently allocated. In addition, Redding and Venables (2003) test empirically 
that the gains from liberalization are conditional on the supply capacity of the liberalizing economy. Particularly for the former socialist countries, they argue that supply-side weaknesses will have to be addressed if the potential benefits of free trade are to be realized. Along the same lines, Hoekman and Javorcik (2004) recognize that production cost, quality, and variety of goods and services are also determining factors for the net benefits that can be acquired from trade liberalization.

In the light of arguments presented above, the supply-side constraint in the process of internationalization of Small and Medium Enterprises (SME) in Kosovo is the starting point of this paper. However, the current paper tests the human-resource related constraints to supply capacities of Kosovo SMEs in foreign markets. In addition, the paper investigates other conventional firm-related factors and how they interact with export activities of SMEs in Kosovo, such as firm size, age, growth, sector, ownership, and level of technology. Drawing on a 2013 survey of 497 SMEs in Kosovo, econometric estimates produce mixed outcomes regarding the relationship between the level of education of the workforce and investment in training with both the propensity (i.e., the incidence of firms entering export markets) and the persistence (i.e., the longevity) in export markets. While the formal education variable generally has negative and statistically significant effect on the propensity to enter foreign markets or the longevity of serving export markets, the training variable reveals the opposite; that is, it reveals positive and highly statistically significant coefficients for both the incidence and persistence of exporting, respectively. These results may indicate the structural problems the education system in Kosovo in general - and in particular the tertiary education - is facing and the distortions it can create in the enterprise sector. In addition, it may simply mean that there is no sufficient demand for highly skilled labor. Other ingredients of the model deliver largely as expected: size and experience matter for export activity of SMEs in Kosovo; prior firm growth rates induce both propensity to enter and persistence of businesses in the export markets; 
and finally, SMEs with product quality certification are more likely to become exporters and to persist longer in export markets.

Next, the paper discusses briefly the theoretical foundations of our study. Further, it discusses the results of our empirical analysis. Finally, the paper summarizes the key findings.

\section{Theory and Hypotheses}

Human capital including education, skill level, training, knowledge accumulation, and dissemination has been discussed extensively in the micro and macro literature. At the macro level, the human resources, including accumulation of knowledge and innovation, take a centre stage in the 'new' growth, trade theory, and economic geography. In the context of endogenous growth theory, knowledge creation and dissemination is seen as the main ingredient of longterm growth (e.g., Romer, 1986). The interpretation of the linkage between the accumulation of human capital and New Trade Theory can be seen in conjunction with the premises of the New Economic Geography. While the traditional neoclassical view of the comparative advantage theory rests on the assumption of constant economies of scale, the introduction of the monopolistic competition in the economic modelling by Stiglitz and Dixit (1977) made it possible to take into account the presence of economies of scale. As a result, the economies of scale enter the theoretical discussion on trade as an additional source of comparative advantage. That is, in the presence of economies of scale, it is the scale of production that determines the gains from comparative advantage. To see how this initially works, one should make a distinction between the internal and external economies of scale. While the former refers to economies of scale at the firm level, the latter refers to the economies of scale at the sector level (or even broader), whereby the cost per unit does not depend on the size of the individual firm but on the size of the sector. In the case of internal economies of scale the size of the domestic market is vital for the international competitiveness 
of firms. Firms operating in relatively large markets tend to have more sales, and hence lower average unit costs, than those operating in smaller domestic markets. Given the cost advantage, firms operating in large domestic markets will find it easier to establish their presence in export markets.

The New Economic Geography enters this discussion through the external economies of scale. External economies of scale arise at the sectoral level when production is concentrated in one or a few locations, thereby reducing the sector's cost without necessarily affecting the size of individual firms within the sector. The geographical concentration of production, also known as the agglomeration process, may give rise to local support industries and/or a larger supply of specialized skilled labor. The concentration of production will likely lead to cost reduction since producers will be able to benefit from the easy and cheap availability of the specialized supply industries and skilled labor, making them also internationally competitive. Contrary to internal economies of scale, external economies generated at the industry level through the geographic concentration of industries provide opportunities for international expansion of small firms as the sources of the firm's competitive advantages lie outside the firm's boundaries (e.g., Krugman, 1991; Krugman and Obstfeld 2003).

Hence, one of the important sources of external economies of scale is the accumulation of knowledge. This argument is closely connected to a feature specific to knowledge: knowledge is a common property resource, and no agent fully receives the benefits of creating it. Otherwise, this problem is known as the appropriability issue, i.e., the inability of 'knowledge producers' to fully appropriate the economic returns from the knowledge produced (for a review of literature related to this, see Gashi, 2007). In this context, dynamic external economies arise when the improvement, which an individual firm achieved in its products or its production technique, is imitated by its competitors; as a result, knowledge spills over from the firm that initially invested in knowledge accumulation to other firms that have not made any specific investment in such knowledge (Mayer, 1996). 
At the firm level, there is a general consensus that no established theory is able to fully explain the dynamics behind a firm's international expansion, and even less so for the internationalization of SMEs. In an extensive survey of the existing internationalization theories ${ }^{3}$, Wright, Westhead and Ucbasaran (2007) acknowledge that a unifying and clear theoretical setting to explain the process of the internationalization of firms is missing. Hence, as Jones and Coviello (2005) argue, it is necessary to integrate multiple theoretical perspectives in order to understand the forces behind the firm's internationalization decisions. This holistic approach, according to Wright, Westhead and Ucbasaran (2007), should take into account firm resources and its environment, strategic choices, and management decisions. These factors, they further argue, will determine the timing, mode, and intensity and sustainability of internationalization.

Micro-level theories including the literature on small firm internationalization place a major emphasis on human resources as a vital ingredient for discovering and exploiting opportunities that lie outside a firm's domestic market. Brush, Edelman and Manolova (2002) argue that relative to their non-internationalized counterparts, human capital is found to be the most important resource associated with internationalized firms. Generally, these theories associate better human resources with higher levels of competitiveness, and firms with a greater knowledge base have greater entrepreneurial capabilities. In addition, they are able to identify potential partners, gather information, and build networks.

In addition, these theories also view the quality of human capital as a source of productivity differentials between firms. This is very important in the context of the internationalization process because according to a new brand of microtheories, a firm's decision to enter and exit export markets depends on the level of firm's productivity and sunk costs (Melitz, 2003; Melitz and Ottaviano, 2008). The Melitz's model of international trade in differentiated products, as it is known, assumes that firms face a degree of uncertainty regarding their future level of 
productivity when making a costly and irreversible investment decision prior to entry. In other words, entering export markets involves sunk costs associated with developing new markets and, in order to cover those costs, productivity must be higher to enable the firm to enter. The literature on the internationalization of small firms acknowledges that the inherent lack of resources constrain even more SMEs to deal with incurred sunk costs (Requena-Silvente, 2005). Thus, more productive firms self-select into export markets. Once the firm enters the export markets, learning and competition effects kick in and enable them to become even more productive (Greenaway, Sousa, and Wakelin, 2004).

Firms endowed with high quality human capital have a higher degree of productivity, and as such they are able to overcome the barriers of the irrecoverable costs associated with entering the foreign market. The literature has provided abundant evidence on the positive association between the education of workforce and firm productivity. Becker in his pioneering work (1962 and 1975) argues that human capital is expected to increase productivity at the firm- and country-level through three broad channels: enhancing productivity when carrying out a given task, increasing the prospects for innovation, and facilitating the adoption and adaptation of new production technologies. A series of studies conducted in the mid-nineties in the United States show that the average educational level of the establishment has a positive and statistically significant effect on the productivity level equally in manufacturing and non-manufacturing sectors (Lynch and Black, 1995 and 1997; Black and Lynch, 1996). Similarly, Jones (2001) finds that educated workers in Ghanaian firms are more productive than workers with no formal education. In addition, the study documents that a higher level of education of the workforce is associated with higher productivity levels. Similar to the results from the United States, the latter study shows that education enhances the productivity in the manufacturing sector. Finally, a recent study by Gashi, Hashi and Pugh (2014) on transition countries identifies a positive relationship between the level of education and the export behavior of firms (i.e., the propensity and intensity of exporting). As we will see later, it seems that 
the results found for all transition countries conceal the true relationship for individual countries, such as in the case of Kosovo.

In addition, training is a mechanism to increase levels of firm productivity, but it is also a means to maintain high levels of productivity within firms (Lynch and Black, 1995; 1997; Black and Lynch, 1996; Acemoglu and Pischke, 1998; Bryan, 2006; Konings and Vanormelingen, 2010). In the case of the United States, Black and Lynch (1996: 265) demonstrate the impact of certain types of employerprovided trainings on an establishment's productivity. An important finding of this study is that there is a lag for the impact of training on an establishment's productivity. For manufacturing, authors find that current training lowers productivity, while past training increases the current productivity. Authors believe that "...initially there are adjusted costs associated with the introduction of new skills and capital into the workplace which are then followed by positive improvements in productivity". Likewise, Konings and Vanormelingen (2010) find similar results for Belgium; according to this study the marginal product of a trained worker is on average over 20 percent higher than that of an untrained worker. They find a slightly higher impact of training in non-manufacturing than on manufacturing sectors.

Before defining the major hypotheses of this research, it is important to introduce the dimension of firm size into the human capital-productivity relationship. This is particularly important for our discussion as our sample is consisted entirely of SMEs and the latter are by definition resource-constrained and also shape the relationship between human capital and productivity. In the context of this relationship, large resource-abundant firms will be able to offer better salaries and more stable jobs. As such, large firms will be able to hire better-endowed workforce and, as Konings and Vanormelingen (2010) argue, this makes large firms generally more productive. There are a number of studies showing that SMEs pay lower wages than larger firms and that SME jobs are less stable. Evans and Leighton (1988) find a positive correlation between size and wage, while Brock and Evans (1989) show that workers in SMEs have shorter tenures and 
are more likely to quit or to be fired. As with an educated workforce, large firms have greater likelihood to train their workforce and offer better prospects for career development, as demonstrated by the recent Western Balkans experience (OECD, 2012). Lynch and Black (1995) explain that the reason why small firms provide relatively less training to their employees is either because of higher per unit costs in the provision of formal training, or that they have more concerns about losing trained employees to competitors. With these findings in mind, our empirical investigations isolate the effects of education and training for different firm size categories.

The nexus human capital-productivity-export produces the following two major hypotheses of the paper:

- Hypothesis 1: Workforce education and training are positively related to the firm's probability of exporting.

- Hypothesis 2: Workforce education and training are positively related to the firm's persistence in export markets.

As pointed out earlier, the empirical investigation will introduce additional supply-side variables, such as the firm size, experience, technological level, growth, foreign ownership, and sector. In line with Melitz's framework and small firm internationalization theories, these dimensions are expected to positively affect both the propensity to export and the persistence in export markets. Taking them in light of Melitz's approach, larger firm sizes are associated with better endowments, and as such these firms are better positioned to face risky international environments. In a similar vein, a resource-based perspective acknowledges that many SMEs may not internationalize due to limited resources to enter foreign markets (Westhead, Wright and Ucbasaran, 2004). In addition, network theory devotes considerable attention to the interaction between small and large firms and the former's international competitiveness. 
In addition, stage theory and strategic choice theory place significant attention to experience in domestic and international markets (Wright, Westhead and Ucbasaran, 2007). In the Melitz's framework, learning-by-doing or learning-byexporting both enhance a firm's productivity. As Syverson (2011: 344) explains: "the very act of operating can increase productivity". With regards to size and experience, we investigate whether the effect of the size or age of the firm is linear or whether variables have quadratic effects (increasing or decreasing). Next, technology - that is, R\&D investments and innovation - is the main ingredient of firm productivity. Small firm internationalization theories generally treat the relationship between technology and internationalization through the lens of resource constraints specific to SMEs.

The rate of past growth determines the current level of productivity. As a matter of fact, in a sample of UK firms, Du and Temouri (2014) show that the interaction between firm growth and productivity growth is a self-reinforcing process. According to them, firms with higher productivity are more likely to grow faster, while high-growth firms are more likely to achieve higher productivity growth. In this context, the literature on the internationalization of small firms argues that the direction of the effect between productivity and growth may be context-specific, according to country, region, or industry (Wright, Westhead and Ucbasaran, 2007). Foreign owned SMEs, on the other hand, are generally more productive and more inclined to exporting than domestic firms. This argument is supported by small firm internationalization theories on the basis of resource availability. The literature shows that for the majority of SMEs the most important mode of entry is direct exporting, because investing abroad is associated with greater risks and higher costs of entry and exit. Hence, for those who have already made this leap (i.e., invested in a foreign country) exporting may seem a feasible option. On a final note, the literature on SME internationalization has devoted significant attention to the relationship between the sector of activity and internationalization. Indeed, the main focus of transaction cost theory is on manufacturing. The evidence on SME internationalization shows that younger 
and manufacturing firms are more likely to be exporters, and they reported higher internationalization intensities - see, for instance, Westhead, Wright and Ucbasaran (2004) in the case of UK SMEs.

\section{Empirical Investigation}

\subsection{Data}

This analysis uses a survey of 497 Kosovo companies that was commissioned by the United Nations Development Program (UNDP) in 2013. ${ }^{4}$ Face-to-face interviews were conducted with the management of the selected companies. The purpose of the survey was to provide more in-depth information on the enterprise sector in Kosovo, with a specific reference to the trade-related developments. The questions collected information on firm's human resources, including overall education of the workforce, education of the production workforce, and training. In addition, the survey covered issues such as size, sector of activity, turnover, investment, technology sophistication, barriers to growth - both internal and external - and other related issues. In total, the survey covered six manufacturing sectors (HS 2-digit) and three service sectors, selected on the basis of their growth potential as revealed by the sector's recent export performance (see Linotte et al., 2013, for information regarding the methodology applied. Overwhelmingly, surveyed firms operate in the manufacturing sectors, with almost half of them in the furniture sector, followed by plastics, and the milling industry. Less than 10 percent of surveyed companies include the ICT sector, communication, and business services. ${ }^{5}$

As Table 1 reports, the sample is dominated by micro and small enterprises, with over 90 percent of the total. Small and medium firms constitute 23 and 8 percent, respectively. A significant portion of these companies engages in export

4 For more details see UNDP (2013) Three Policy Assessments for Priority Trade and Human Development Topics. http://www.ks.undp.org/content/kosovo/en/home/library/ poverty/three-policy-assessments-for-priority-tradeand-human-developmen/.

5 Manufacturing sectors include the following: plastics; beverages, spirits and vinegar; salt, sulphur, earth, and stone, plastering materials, lime and cement; furniture, edible fruits and nuts; and the milling industry. 
activities, around 35 percent. Generally the firms are young, with an average of 12 years, and inexperienced in export markets. On average, companies start exporting after around 8 years, while over 50 percent started exporting in the first five years. For a quite significant number of businesses (20 percent) the establishment and the year of exporting correspond. Next, only nine surveyed firms in the sample are foreign, with only one fully foreign. These foreign firms are micro and small sized, while only six are engaged in export activities. Furthermore, a third of the companies in 2012 report growth compared to 2011. With regards to education, on average, only 20 percent of the workforce has a university degree, while a third of companies have provided training for their workforce. Finally, in the context of the technology, over 16 percent of firms have obtained a quality certification.

Table 1: Descriptive Statistics

\begin{tabular}{|c|c|c|c|c|c|c|}
\hline \multirow{2}{*}{ Variables } & \multirow{2}{*}{ Mean } & \multirow{2}{*}{ St. dv. } & \multirow{2}{*}{ Min } & \multirow{2}{*}{$\operatorname{Max}$} & \multicolumn{2}{|c|}{ Fractions } \\
\hline & & & & & 1 & $\mathbf{0}$ \\
\hline \multicolumn{7}{|l|}{ Dependent variables } \\
\hline Exp. vs. imp. (exp) & - & - & - & - & 31.65 & 68.35 \\
\hline Export age (expage) & 1.84 & 3.71 & 0 & 29 & - & - \\
\hline \multicolumn{7}{|l|}{ Independent variables } \\
\hline Log of lagged firm size (Insize) & 3.9 & 0.6 & 1 & 210 & - & - \\
\hline Log of firm experience (lnage) & 12.10 & 10.23 & 1 & 95 & - & - \\
\hline Foreign ownership $\left(f_{\text {_own }}\right)$ & - & - & - & - & 1.83 & 98.17 \\
\hline Sector $(\operatorname{sect})$ & - & - & - & - & 86.79 & 13.21 \\
\hline Firm growth $\left(f_{\text {_growth }}\right)$ & - & - & - & - & 33.13 & 66.87 \\
\hline Workforce education $(e d u)$ & 19.96 & 28.07 & 0 & 100 & - & - \\
\hline Training (train) & - & - & - & - & 35.23 & 64.77 \\
\hline Tech. sophistication $\left(t_{-}\right.$sof $)$ & - & - & - & - & 40.98 & 59.02 \\
\hline Quality certification (iso) & - & - & - & - & 16.32 & 83.68 \\
\hline
\end{tabular}

Source: Author's calculations.

\subsection{Econometric Specification}

This investigation utilizes two different dependent variables. The first dependent variable is a binary variable that takes a value of one if the firm is an exporter and 
0 otherwise. The second dependent variable is the export experience of firms, that is, the years since the firm started exporting. Typically, apart from the probability of entering the export markets, similar studies try to estimate the dimension of intensity of sales into export markets (Gashi, Hashi and Pugh, 2014). However, the database used in this case does not contain such information. There is an advantage to using the experience in the export markets as a dependent variable rather than export intensity measures, because intrinsically it takes into account the sunk-cost dimension of entering or exiting foreign markets.

This study employs a binary regression model (i.e., the probit model) and a censored regression model (i.e., the tobit model) to test our hypotheses. The probit model can be applied in cases when the dependent variable takes only two values (i.e., it is binary), as in our case: exporter and non-exporter, respectively. Generally, probit models yield efficient and consistent results, and the outcomes are relatively easy to interpret. Tobit models, on the other hand, are used in cases when the observations of the dependent variable are skewed in one of the extremes of the distribution. As in our case, two-thirds of observations are zeros, representing non-exporters, while the rest are exporters. Tobit models are best suited for our investigation because they take into account the dichotomy of the firm's decision process - first: export or not; and second: if export, how long to serve in foreign markets. This double decision-making process is captured by two types of marginal effects in a tobit model. ${ }^{6}$ Wooldridge (2002) distinguishes between the 'unconditional' marginal effects that account for the effect of changing values of the independent variables on the probability that exporting will take place at all. In addition, 'conditional' marginal effects account for changes in the expected (or predicted) value of exports ( $y$ ) for the subpopulation of firms for which exporting activity is observed $(y>0)$. This is a significant advantage of tobit models, and as such we will primarily rely on these estimates, whereas probit estimates will be presented largely as a robustness check. Our tobit model takes the following form:

6 For more details on these regression models, see Maddala (1992), Wooldridge (2002), and Greene (2003). 
$y_{i}=\left\{\begin{array}{ll}\beta_{0}+\beta_{1} \ln \text { size }+\beta_{2} \ln s i z e^{2}+\beta_{3} \ln a g e+\beta_{4} \ln a g e^{2}+\beta_{5} f_{-} \text {own }+\beta_{6} \text { sect }+ \\ +\beta_{1} f_{-} \text {growth }+\beta_{2} e d u+\beta_{3} \text { train }+\beta_{4} t_{-} \text {sof }+\beta_{5} i s o+e_{i} & \text { for exporters } \\ 0 & \text { for non-exporters }\end{array}\right\}$

whereas the probit model takes the following form:

$P\left(y_{i}=1 \mid x\right)=\Phi\left(\begin{array}{l}\beta_{0}+\beta_{1} \ln \text { size }+\beta_{2} \ln \text { size } e^{2}+\beta_{3} \ln \text { age }+\beta_{4} \ln a g e^{2}+\beta_{5} f_{-} \text {own }+\beta_{6} \text { sect }+ \\ +\beta_{1} f_{-} \text {growth }+\beta_{2} e d u+\beta_{3} \text { train }+\beta_{4} t_{-} \text {sof }+\beta_{5} i s o+e_{i}\end{array}\right)$

In both cases $y$ denotes the dependent variable conditional on the explanatory variables discussed above. In the case of the probit model, $\Phi$ denotes the cumulative distribution function.

\section{Results}

Both the probit and tobit models perform rather well. Post-estimation tests for the tobit model are scarce, although a diagnostic check has been proposed by Woodridge (2002) and Greene (2003) that assesses the appropriateness of the tobit estimates by comparing the outcomes of the latter with the probit estimates. The results of the diagnostic check show very similar outcomes of both models, suggesting that the tobit model provides consistent and unbiased estimates for the sample of SMEs in Kosovo. With regards to other specification issues, such as measures of fit (Pseudo $R^{2}$ ) and indicators measuring the joint and partial significance of coefficients ( $L R c h i^{2}, P r o b>c h i^{2}$, and the Wald test), it seems that both models work rather well. In addition, few other specification tests have been performed for probit estimates; no specification error or multicollinearity issue has been detected. ${ }^{7}$ Finally, another concern that had to be dealt with is the potential endogeneity of the independent variables. Apart from the size variable,

7 The results from the diagnostics analysis can be obtained from the author. Note that the econometric model has also been performed using ordinary least squares (OLS). In a sense, the dependent variable 'export age' can also be treated as a continuous variable. Results are very similar with those from the tobit and probit models. Although the post-estimation tests show that the OLS model is specified well and does not suffer from multicollinearity, there is an issue with heteroskedasticity, skewness, and kurtosis. However, the robust standard errors should be able to diminish the negative effect of the latter. These results can be obtained from the author. 
none of the other variables give an indication that they may be endogenous to the model based on the way they were built. As a result, instead of using current levels of employment to establish the size variable, we use the lagged number of employees (i.e., number of employees in 2011).

Table 2 presents the estimated marginal effects from both models; in the case of the tobit model, marginal effects are broken down into unconditional and conditional effects. In brackets we report cluster-robust standard errors (clustered on sectors). The results obtained are consistent with the direction of the effect prevailing for all variables in both models, although the magnitude and the statistical significance differ slightly in some cases. ${ }^{8}$ The latter refers specifically to the variable of the education of the workforce, defined as a share of the employees with higher education in the total workforce. Although the sign is consistent, the variable is statistically insignificant in the tobit model, while in the probit model it is statistically significant at 5 percent. Quantitatively, for the probit estimate, a 1 percent increase in the share of employees with high education in the total workforce decreases the probability of entering export markets by 0.002 . The breakdown of the education variable based on the firm size (i.e., the percent of educated workforce in micro, small, and medium firms) indicates that a statistically significant negative effect is generated in the category of small firms.?

8 The tobit and probit models have been performed only for the manufacturing sector; the model has been performed in two variations - first including the overall education and second including the education of workforce in the production process. In both cases the results are very similar with those from the full sample. In terms of direction, the results are all the same, while the size of coefficients is generally higher, especially for statistically significant variables. One other result that stands out is the positive and statistically significant coefficient of foreign ownership (results can be obtained from the author).

9 Results can be obtained from the author. 
Table 2: Regression Results

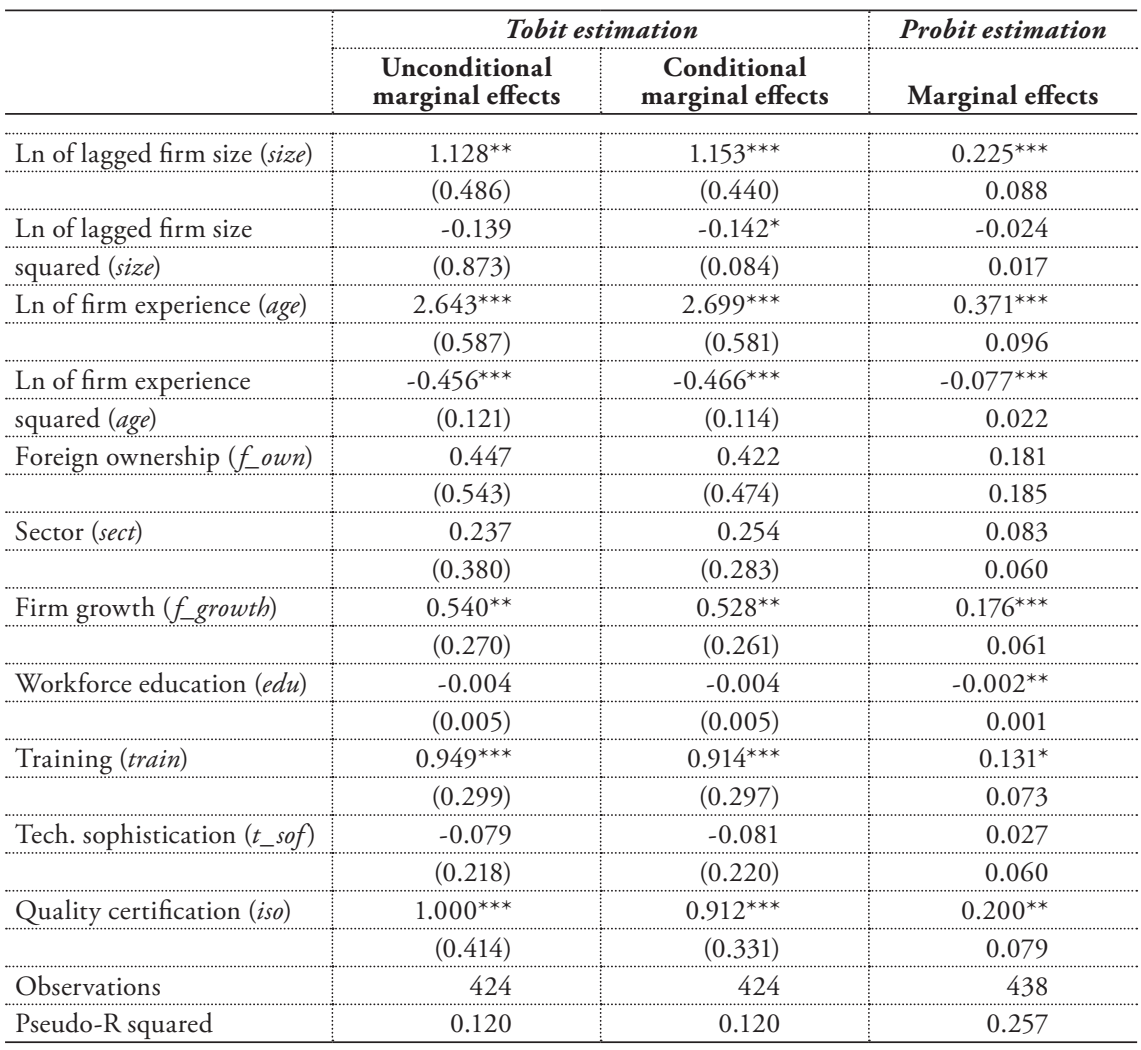

Note: Robust standard errors in parentheses. Levels of significance: ${ }^{* * *} \mathrm{p}<0.01,{ }^{* *} \mathrm{p}<0.05,{ }^{*} \mathrm{p}<0.1$.

Source: Author's calculations.

The negative - or even statistically insignificant in the case of tobit - relationship between education and the probability of entering export markets may seem unexpected. However, in the transition countries this outcome has been observed before, albeit in the context of firm growth. Bartlett and Bukvič (2001) report the same result for Slovenia in its early days of transition. In their model of SME growth, they use university education to indicate a salient characteristic of the entrepreneur. The statistically significant negative coefficient indicates that entrepreneurs with a university degree have lower rates of growth than other 
firms. In addition, Xheneti and Bartlett (2012: 616) find similar results for Albania. In the context of growth constraints of SMEs in Albania, they find that the entrepreneur has a significant negative effect on SME growth. They argue that "this may be related to the fact that university level education in Albania has had little business-related content, and so does not lead to improvement in ability to manage an enterprise and to cope with a risky business environment" (Xheneti and Bartlett, 2012: 616).

The outcomes of the studies discussed above resonate with the reality in Kosovo. Results give indications for the deep-rooted problems of the education system in Kosovo in general, in particular the problems that tertiary education is facing as well as the distortions it can create in the enterprise sector. Many factors have contributed to the existing situation - for example, like in other Western Balkan countries (Bartlett and Arandarenko, 2012; Bartlett, Johansen and Gatelli, 2012) - and reforms in the education system of Kosovo are lagging. Public investments have been low, while corruption is evident. There is little quality control in private tertiary education, and incentives for new vocational training providers are lacking. As a result, the products of the education system in Kosovo either do not have the right skill-set, or their skill-set does not match labor market needs. This is confirmed by HDR (2010), which argues that there is a large mismatch between the subjects learned in school and the skills needed to participate in the job market. Similarly, the World Bank (2014) argues that the degree, quality, and mix of skills of the Kosovar work force fall short of the required levels in modern market economy. In addition, a set of in-depth interviews conducted with medium-sized companies in Kosovo shows that the educational background of potential workers is very disproportional to their business needs (HDR, 2012).

However, there may be explanations beyond the education system regarding the negative (or statistically insignificant relationship) between education and export decisions. These results may also be seen in conjunction with the structure of Kosovo exports; while Kosovo generally exports low-value high-labor intensity goods, there is no major demand in the market for people with a university 
degree. In the two recent surveys with Kosovo SMEs (UNDP, 2012; SEECEL, 2013) the skill and education of available workforce rates very low in the list of barriers to doing businesses, literally approaching the bottom in the ranking of critical business barriers. According to the SEECEL (2013) survey, Kosovo entrepreneurs relative to their Balkan colleagues rate very low for the shortage of skilled and experienced employees. Combining these perceptions with the low level of knowledge and skills amongst Kosovo adults and education standards among Kosovo's young people, the HDR (2012) concludes that Kosovo is settling for low-skilled, low-value activities. ${ }^{10}$ As a result, the Report argues, there is simply not enough demand for the kind of skills that predominate in the industrialized world, where the race for talents is fierce, because SMEs are aware that the quality of human resources plays a key role in firm's innovation capacity, productivity, and international competitiveness (for the EU context, see European Commission, 2011). The findings of the survey provide another important insight: the perceptions of businesses on the importance of skills and education vary with size and sector. Bigger companies put a greater emphasis on the need for better skills and education of the workforce compared to small and micro firms. In addition, ICT, food processing industries, and some sub-sectors in agriculture perceive the lack of skills and knowledge as a serious obstacle to their operations.

Yet another explanation of the negative result may be found in the cost of the high-skilled workforce in Kosovo. World Bank (2010) argues that Kosovo has one of the lowest wage levels in the region; however, according to the study, Kosovo's wage competitiveness is very strong in low-skill sectors but is much less in high-skill sectors due to the high-skill premium. The high cost of a qualified workforce is evidenced in a series of interviews with medium-sized companies reported in the HDR (2012).

As the education system does not deliver, it seems that internationally oriented SMEs are forced to allocate their limited resources to increasing the capacities 
of their workforce through training and other forms of personnel development. However, this does not apply to small companies operating at the low-value spectrum who are unwilling to invest in increasing workforce capacities (HDR, 2012). With regards to the firm investment in training - represented by a dummy variable taking the value of 1 for companies who have provided training for their workforce and 0 otherwise - a discrete change from 0 to 1 , according to the tobit marginal effects, increases the likelihood of exporting and the export persistence by over 0.9 of the percentage point. The breakdown of the training variable based on the firm size (i.e., the interaction term of the training variable with the variables for micro, small, and medium firms) indicates that a statistically significant positive effect is produced only for micro firms. ${ }^{11}$ Despite the positive effect on the firm's performance, it seems that only a fraction of Kosovo businesses resort to training its personnel. According to World Bank (2014), the training provided by Kosovo businesses is only one-fifth of the South East Europe average, and one-fourth of that in Europe and Central Asia region. The report believes that the reason why Kosovar businesses may be more reluctant to provide training could be related to the concerns about losing trained employees to competitors. In any case, for SMEs, investment in training must be bound by resource constraints, which are primarily financial.

The results for other variables are largely consistent with the predictions. The coefficient of the natural logarithm of the lagged size is positive and statistically significant. The quadratic function for size borders the conventional levels of significance only in the case of conditional marginal effects. This result confirms the expectations that larger firms are associated with larger probabilities to enter and serve longer in export markets. Typically, this outcome is a function of the greater human, technological, and financial resources that come with the size of the company. Better resource-endowed firms possess the necessary resources to deal with sunk costs and high-risk foreign environments. Foreign markets are by definition riskier environments than domestic ones due to institutional and cultural differences, as well as differences in consumer tastes and preferences. 
Similarly, the natural logarithm of age is positive and statistically different from zero at the 1 percent level. ${ }^{12}$ However, estimates indicate diminishing returns of the experience since the natural logarithm of age squared is negative and statistically significant. While learning-by-doing effects increase firm productivity - and with that the chances of firms to enter and serve export markets longer - as expected, the effect fades with aging of the firm. With regards to the previous growth levels (i.e., the variable enters the equation as a dummy taking 1 for firms that have increased the employment levels from previous periods and taking 0 otherwise) the result is positive and significant. We argued that in general firm growth and productivity reinforce each other; at least in this investigation the results are consistent with the proposition that the direction of the effect runs from growth to entering and serving export markets through, presumably, productivity increases. It is likely that the growing firms accumulate capacities - both human and technological - increasing at the same time the levels of productivity, and with that also changing their odds to export.

Slightly surprising outcomes are the statistically insignificant coefficients for foreign ownership (i.e., if the company is partially or fully foreign owned) and the sector of activity (i.e., a dummy variable taking a value of 1 for manufacturers and 0 otherwise). Regarding the former, it is likely that the outcome has been affected by the fact that foreign capital flows in Kosovo have been concentrated largely in non-productive activities, primarily real estate. In addition, the outcome can be purely technical, that is, as a result of a small number of foreign owned firms in the sample (see Table 1). Regarding the latter, there are no statistically significant differences between manufacturing and services in the probability of exporting and longevity of serving export markets. One should not be surprised by this

12 In a sense, the dependent variable reflects both age factors and duration of exporting. However, as we point out, the tobit model estimates a dual decision-making process, first, decision to enter the foreign markets, and, second, decision to stay/exit foreign markets. Hence, the point raised would make sense in the context of the second point rather than the first. In order to see if the results would change, the regressions in the tobit model have been performed without age variables. The results show no significant changes from the original model (i.e., including age variables). Only the firm growth variable shows a drop in the statistical significance of the coefficient (bordering 10 percent), while the other variables are very similar in magnitude and direction. The STATA log file containing the results of this estimation is submitted together with the current draft of the paper. 
outcome as in the post-war Kosovo services have been performing reasonably well in foreign markets (Gashi and Pugh, 2014).

The last two factors consider the level of technology embodied in the surveyed SMEs. While the self-assessment by firms of their levels of technological sophistication relative to their competition is not statistically different from zero, having a quality certificate (e.g., ISO) - defined as a dummy variable taking values of 1 for those firms with international quality certificate and 0 otherwise increases the chances of entering the export market and serving them longer. The latter result is of high significance for the expansion of Kosovo SMEs especially in the EU market once the FTA is in place. Theoretically, it may also be argued that there is reverse causation in this relationship, i.e., that firms that intend to export, or even expand exporting activities to other foreign markets, are more likely to adopt quality standards in the first place. However, from a policy perspective this does not invalidate the argument that increasing the quality of services and facilitating the quality certification is an important precondition to expand in foreign markets.

The European Commission places a significant weight on international standards and considers them a major factor in supporting innovation, growth, and competitiveness. In terms of competitiveness, the EC report (2012: 24) acknowledges that:

"Standards have an important role to play in supporting the competitiveness of businesses in the global market, by helping to improve the products and services they provide, and by enabling access to foreign markets and businesses. Standards are trade enhancing because of their cost-decreasing effect and because they reduce information asymmetries between the supply and demand sides, especially in the case of cross-border trade."

With 80 percent of trade liberalized, adoption of international standards for Kosovo SMEs - and indeed the entire enterprise sector - is vital for international expansion. The liberalization will not guarantee market access to foreign markets 
unless product standards are met. In addition, as the report argues, adoption of international standards will also improve internal organization capabilities and processes within firms, which are typical shortcomings in Kosovo SMEs.

\section{Conclusion}

The supply-side constraints that the Kosovo economy is currently facing place a question mark on the potential benefits from the trade liberalization with the EU. Using a sample of around 500 SMEs in Kosovo, this paper sheds light on the relationship between human capital, a supply-side factor, and other firm-related variables to firm exporting decisions (i.e., the decision to export and persistence in export markets). This investigation relies on small firm internationalization theories, primarily on the Melitz's dynamic model of export participation. The probit and tobit estimates provide mixed results; while the outcome for the education coefficient ranges from statistically significant and negative to statistically insignificant and negative, the investment in training variable shows a consistent positive and statistically significant relationship with the export propensity and longevity of serving export markets. There are a number of potential explanations for this. First, these results are consistent with the argument that the education system in Kosovo does not necessarily provide the right level and/or mix of skills required by the private sector, which in turn forces SMEs to invest a significant proportion of their limited resources in training to increase the knowledge and skills of their workforce. Second, while Kosovo generally exports low-value high-labor intensity goods, such as primary and intermediate goods, presumably there is no substantial demand in the market for a highly skilled workforce. Finally, it may be too costly for resource-constrained SMEs to hire highly educated people due to the high-skill premium in Kosovo. Other factors that affect the decisions of firms to enter and serve export markets are found to be firm size, experience, past growth levels, and adoption of quality standards. 
The present study contributes to the understanding of the internationalization process of Kosovo SMEs by providing empirical-based evidence on the factors that influence the decision to export and persist in export markets. The outcomes of this study complement the results from recent studies on Kosovo and the region, regarding the importance of human capital as a productivity-enhancing factor and its importance in SMEs export decisions. While the need to increase supply-side capacities of the Kosovo economy has been established, this study demonstrates that upgrading human capital seems to be an important building block in resolving the supply-side conundrum in the SME internationalization process.

However, despite its merits, this paper has a number of limitations. While it concentrates on a mix of manufacturing and service industries, it may not be sufficient to generalize the outcomes for the entire enterprise sector in Kosovo, especially since it concentrates on better-performing industries. In addition, it cannot isolate firm-specific developments from the developments in the firm's environment, especially relationships with large firms. Moreover, a number of questions remain unanswered regarding the relationship between the human capital variables and export decisions. For instance, data limitations made it impossible to look into the types of trainings and export decisions. Moreover, data restrict us in analyzing the dynamics of the relationship between the human capital and export decisions of SMEs. This would be particularly important in analyzing the relationship between training and productivity over time and to determine how that affects the export decisions of SMEs.

The outcomes of the investigation may serve policy-makers in Kosovo to adjust policy prescriptions by incorporating measures aiming at enhancing supplyside capacities of the economy, specifically upgrading the human capital. These policies should be directed, when possible, towards SMEs as the latter are affected disproportionately by barriers to enter the external markets. However, this is not a straightforward issue, especially taking into account the broad spectrum of policies that human resources interact with and also the heterogeneity in the 
SMEs internationalization process. Regarding the latter, Wright, Westhead and Ucbasaran (2007: 1015) argue that policy prescriptions should take into account firm heterogeneity, starting "from those that do not and cannot internationalize to those that internationalize from their inception”. Regarding the former, policy directions suggested to former Central Europe socialist countries in their early days of transition may be used as a useful guide for reforming the education system in Kosovo (World Bank, 1996). The record of transition countries shows that reform in the educational system should primarily aim at filling the gaps in knowledge as well as reshaping the skills of the workforce so it could meet the needs of a market system. Closing the skills gap means giving workers more transferable and marketable skills. As OECD (2012) argues, this is particularly important for sectors trading with the EU.

However, upgrading human capital is a necessary but not sufficient condition to fully utilize the benefits of the market liberalization. In addition to wellendowed human resources, Hoekman and Javorcik (2004) argue that policy attention should be focused, among others, on creating a stable and conducive business environment. According to OECD (2012) and UNDP (2012), over the medium term it is paramount for Kosovo institutions to focus on improving their business environment, including developing efficient and transparent legislation and regulations, enforcing contracts, tackling excessive red-tape, and reducing evasion and informality. Improvements in the business climate may have an effect on firms' decisions to invest in the development of human capital. As Bartlett and Arandarenko (2012) argue, once the environment becomes more business-friendly and the uncertainties are reduced, firms may be willing to invest more for on-the-job-training and workforce development. 


\section{Literature}

Acemoglu, Daron and Jörn-Steffen Pischke, 1998, "Why Do Firms Train? Theory and Evidence", Quarterly Journal of Economics, 113(1), pp. 79-119. http:// dx.doi.org/10.1162/003355398555531

Bartlett, William and Mihail Arandarenko, 2012, "The Labour Market, Skills and Growth in the Western Balkans: An introduction" in Mihail Arandarenko and William Bartlett, eds., Labour Market and Skills in the Western Balkans, pp. 3-15, Belgrade: Grafolik.

Bartlett, William and Vladimir Bukvič, 2001, "Barriers to SME Growth in Slovenia”, MOST, 11(2), pp. 177-195.

Bartlett, William, Jens Johansen and Debora Gatelli, 2012, "Skills Gaps and Mismatches in the Western Balkans: A Comparative Analysis", in Mihail Arandarenko and William Bartlett, eds., Labour Market and Skills in the Western Balkans, pp. 19-35, Belgrade: Grafolik.

Becker, Gary, 1962, "Investment in Human Capital: A Theoretical Analysis", Journal of Political Economy, 70(5), pp. 9-49. http://dx.doi.org/10.1086/258724

Becker, Gary, 1975, Human Capital: A Theoretical and Empirical Analysis, with Special Reference to Education, 2nd Edition, New York: Columbia University Press.

Bhagwati, Jagdish, 2002, Free Trade Today, Princeton: Princeton University Press.

Black, Sandra and Lisa Lynch, 1996, "Human-Capital Investments and Productivity", American Economic Review, 86(2), pp. 263-267.

Brock, William and David Evans, 1989, "Small Business Economics", Small Business Economics, 1(1), pp. 7-20. http://dx.doi.org/10.1007/BF00389913

Brush, Candida, Linda Edelman and Tatiana Manolova, 2002, "The Impact of Resources on Small Firm Internationalization”, Journal of Small Business Strategy, 13(1), pp. 1-17. 
Bryan, Jane, 2006, "Training and Performance in Small Firms", International Small Business Journal, 24(6), pp. 635-660. http://dx.doi. org/10.1177/0266242606069270

Correa, Paulo, Dayoub, Mariam and Manuela Francisco, 2007, "Identifying Supply-Side Constraints to Export Performance in Ecuador: An Exercise with Investment Climate Survey Data”, World Bank Policy Research Working Paper, No. 4179, Washington, DC: World Bank.

Dixit, Avinash and Joseph Stiglitz, 1977, "Monopolistic Competition and Optimum Product Diversity", American Economic Review, 67(3), pp. 297-308.

Du, Jun and Yama Temouri, 2014, "High-Growth Firms and Productivity: Evidence from the United Kingdom", Small Business Economics. http://dx.doi. org/10.1007/s11187-014-9584-2

European Commission, 2011, Identification of Future Skills Needs in Micro and Crafts (-Type) Enterprises up to 2020, http://ec.europa.eu/enterprise/policies/ sme/promoting-entrepreneurship/files/skillsneeds_final_report_final_180211_ en.pdf (accessed October 25, 2014).

European Commission, 2012, Using Standards to Support Growth, Competitiveness and Innovation, http://ec.europa.eu/enterprise/policies/sme/regional-smepolicies/ documents/no.2_sme_standards_en.pdf (accessed August 25, 2014).

Evans, David and Linda Leighton, 1988, "Why do Smaller Firms Pay Less?", The Journal of Human Resources, 24(2), pp. 299-318.

Gashi, Petrit, 2007, "Export Behaviour and the Small and Medium Enterprise Sector in South Eastern Europe, with Special Reference to Kosova", Staffordshire University, unpublished Ph.D. thesis.

Gashi, Petrit and Geoff Pugh, 2014, "Kosovo - EU Trade Relations: A Dynamic Poisson Approach", unpublished paper.

Gashi, Petrit, Iraj Hashi and Geoff Pugh, 2014, "Export Behaviour of SMEs in Transition Countries", Small Business Economics, 42(2), pp. 407-435. http:// dx.doi.org/10.1007/s11187-013-9487-7 
Greenaway, David, Nuno Sousa and Katharine Wakelin, 2004, "Do Domestic Firms Learn to Export From Multinationals?", European Journal of Political Economy, 20(4) , pp. 1027-1043. http://dx.doi.org/10.1016/j. ejpoleco.2003.12.006

Greene, William, 2003, Econometric Analysis, 5th ed., New Jersey: Prentice Hall.

Hoekman, Bernard and Beata Javorcik, 2004, "Policies Facilitating Firm Adjustment to Globalization”, Oxford Review of Economic Policy, 20(3), pp. 457473. http://dx.doi.org/10.1093/oxrep/grh027

Jones, Marian and Nicole Coviello, 2005, "Internationalization: Conceptualising an Entrepreneurial Process of Behaviour in Time", Journal of International Business Studies, 36, pp. 284-303. http://dx.doi.org/10.1057/palgrave.jibs.8400138

Jones, Patricia, 2001, “Are Educated Workers Really More Productive?", Journal of Development Economics, 64(1), pp. 57-79. http://dx.doi.org/10.1016/S03043878(00)00124-3

Konings, Jozef and Stijn Vanormelingen, 2010, “The Impact of Training on Productivity and Wages: Firm Level Evidence”, IZA Discussion Paper, No. 4731, Bonn: IZA.

Krugman, Paul and Maurice Obstfeld, 2003, International Economics: Theory and Policy, 6th Edition, Reading: Addison-Wesley.

Krugman, Paul, 1991, Geography and Trade, Cambridge: The MIT Press.

Linotte, Daniel, Petrit Gashi, Rron Dalladaku, Buline Mahmudi, Merita Fetahu and Arjeta Islami, 2013, "Preparing Kosovo for the Trade Aspects of the Stability and Association Agreement Negotiations with the EU", part of the EU funded project "Further Development of Kosovo's Trade Policy" implemented by GFA Consulting Group/ACE/CARDNO.

Lynch, Lisa and Sandra Black, 1995, "Beyond the Incidence of Training: Evidence from a National Employers Survey”, NBER Working Paper, No. 5231, Cambridge: NBER. 
Lynch, Lisa and Sandra Black, 1997, "How to Compete: The Impact of Workplace Practices and Information Technology on Productivity", Centre for Economic Performance Discussion Paper, No. 376, London: CEP.

Mayer, Jörg, 1996, "Implications of New Trade and Endogenous Growth Theories for Diversification Policies of Commodity-Dependent Countries", UNCTAD Discussion Papers, No. 122, Geneva: UNCTAD.

Melitz, Mark, 2003, "The Impact of Trade on Intra-Industry Reallocations and Aggregate Industry Productivity", Econometrica, 71(6), pp. 1695-1725. http:// dx.doi.org/10.1111/1468-0262.00467

Melitz, Mark and Gianmarco Ottaviano, 2008, "Market Size, Trade, and Productivity”, Review of Economic Studies, 75(1), pp. 295-316. http://dx.doi. org/10.1111/j.1467-937X.2007.00463.x

OECD, 2012, SME Policy Index: Western Balkans and Turkey 2012: Progress in the Implementation of the Small Business Act for Europe, Paris: OECD Publishing, http://dx.doi.org/10.1787/9789264178861-en.

Redding, Stephen and Anthony Venables, 2003, "Geography and Export Performance: External Market Access and Internal Supply Capacity”, NBER Working Paper, No. 9637, Cambridge: NBER.

Requena-Silvente, Francisco, 2005, "The Decision to Enter and Exit Foreign Markets: Evidence from UK SMEs”, Small Business Economics, 25(3), pp. 237253. http://dx.doi.org/10.1007/s11187-003-6460-x

Romer, Paul, 1986, "Increasing Returns and Long-Run Growth", Journal of Political Economy, 94(5), pp. 1002-1037. http://dx.doi.org/10.1086/261420

SEECEL, 2013, Training Needs Analysis for SMEs: Western Balkans and Turkey's Experience, study commissioned by the European Union and implemented by South East European Centre for Entrepreneurial Learning, http://en.hgk.hr/ files/2013/06/tna_final_regional_results10.pdf (accessed October 25, 2014).

Syverson, Chad, 2011, "What Determines Productivity?", Journal of Economic Literature, 49(2), pp. 236-365. 
UNDP, 2010, Kosovo Human Development Report 2012: Social Inclusion, Prishtina: Grafika Rezniqi.

UNDP, 2012, Kosovo Human Development Report 2012: Private Sector and Employment, Prishtina: Grafika Rezniqi.

Westhead, Paul, Mike Wright and Deniz Ucbasaran, 2004, "Internationalization of Private Firms: Environmental Turbulence and Organizational Strategies and Resources", Entrepreneurship and Regional Development, 16(6), pp. 501-522. http://dx.doi.org/10.1080/0898562042000231929

Wooldridge, Jeffrey, 2002, Econometric Analysis of Cross Section and Panel Data, Cambridge: MIT Press.

World Bank, 1996, World Development Report: From Plan to Market, Washington DC: The World Bank.

World Bank, 2010, Kosovo - Unlocking Growth Potential: Strategies, Policies, Actions, Report No. 53185-XK, Washington DC: The World Bank.

World Bank, 2014, Technical Analysis and Policy Recommendations for Enhancing Employment and Professional Training Interventions in Kosovo: A Contribution to the Sectoral Strategy for Employment and Social Welfare (2014-2020), forthcoming.

Wright, Mike, Paul Westhead and Deniz Ucbasaran, 2007, "Internationalization of Small and Medium-sized Enterprises (SMEs) and International Entrepreneurship: A Critique and Policy Implications", Regional Studies, 41(7), pp. 1013-1029. http://dx.doi.org/10.1080/00343400601120288

Xheneti, Mirela and William Bartlett, 2012, "Institutional Constraints and SME Growth in Post-communist Albania", Journal of Small Business and Enterprise Development, 19(4), pp. 607-626. http://dx.doi.org/10.1108/14626001211277424 